\title{
Genetic drift in small and recently founded populations of the marine snail Littorina Saxatilis
}

\author{
K. Janson
}

Tjärnö Marine Biological Laboratory, PI 2781, S-452 00 Strömstad, Sweden.

The intertidal snail, $L$. saxatilis lacks a pelagic stage and migration between populations inhabiting different islands is rare. Small skerries, which are very young habitats, due to the proceeding post-glacial elevation of land, are likely to have been populated by small groups of snails. Mayr's "founder principle" predicts a "genetic revolution" in populations established in this way. Allozyme data, however, reveal but a slight decrease in the level of heterozygosity within these skerry populations, as compared to those of islands and mainland. A probable explanation for this is that although the founding group may consist of only one fertilised female, sperm storage, year-round reproduction, and density-dependent selection enable such populations to expand rapidly in a formerly empty habitat. As has been shown by Nei and coworkers, this will largely impede the loss of genetic variation during the founder event. Isolated populations of $L$. saxatilis indicate that founder events need not lead to drastic genetic alterations.

\section{INTRODUCTION}

Random genetic drift is often advocated an important evolutionary force when, for example, a population is subdivided into small breeding units, or if a large population is forced to pass through a size bottleneck. In these situations, sampling errors will give rise to random loss or fixation of alleles within polymorphic loci that are not subject to unduly strong selection. Population subdivision is one premise essential to Wright's "shifting balance" theory (Wright, 1932), while population bottlenecks are central to various founder models (e.g., Mayr, 1963; Carson, 1975; Templeton, 1980). Random drift is perhaps most typically exemplified by Mayr's "founder principle", which predicts genetic divergence, reduced genetic variation, and increased homozygosity in a population founded by a small number of individuals. The resulting "genetic revolution" will enable new forms or species to be formed (Mayr, 1963). There are several criticisms of the predictions of Mayr's model. For example, Lewontin (1965) emphasises that only rare alleles will be lost during a founder event and these contribute only marginally to the overall genetic variability. Further remarks are that although a genetic revolution is possible within an extremely small and isolated population, this type of population will probably go extinct soon after being established (Lande, 1980). These points have cast doubts on the real significance of founder effects in the origins of species (Barton and Charlesworth, 1984).

Nei et al. (1975), and Chakraborty and Nei (1977) analyse the quantitative effects of a population bottleneck on gene heterozygosity in neutral loci. They find that, if a population increases its size after a bottleneck, the minimum level of heterozygosity due to stochastic events, will be attained soon after the bottleneck. The reduction in heterozygosity will thus depend crucially on the rate of expansion as well as on the effective size. Furthermore, the drop in heterozygote level will persist over a large number of generations (a numaber approximately equal to the reciprocal of the mutation rate; Nei et al., 1975).

Although a theoretical framework has emerged from the work by Nei and others, data from natural populations are scarce, and the role of bottlenecks in the evolution of natural populations is far from settled. Here I test some predictions of such theories about genetic effects following population bottlenecks. The study comprises an examination of the levels of genetic variation in isolated natural populations which are likely to have passed through size bottlenecks. By choosing recently 
established populations it is possible to assume that the effects of mutations are small.

The marine intertidal snail Littorina saxatilis is a suitable organism for the purposes of this study as it has a direct development and lacks a pelagic dispersal stage, and populations have recently been established on minute rocky islands "skerries". The post-glacial elevation of land is at present $0.25 \mathrm{~m}$ per 100 years in the northern parts of the Swedish west coast. As a consequence, skerries and small islands have emerged within the last few hundred years through the water surface. The intertidal zones of several of these skerries are populated by $L$. saxatilis and, as I will argue, small founder groups of perhaps only one fertilised female, are the likely origin of each population. I have assayed the effects of genetic drift during the founder event of these populations from allozyme patterns at a number of enzyme loci which seem to be largely neutral (Janson and Ward, 1984).

\section{MATERIALS AND METHODS}

A total of 25 populations of $L$. saxatilis were sampled. Of these, 13 were from small habitats ("skerries") of 2 to $200 \mathrm{~m}^{2}$ size, and located between 3 to $2500 \mathrm{~m}$ from the nearest island. Seven were from intermediate sized habitats ("islands"), about 400 to $10^{4} \mathrm{~m}^{2}$ large, and in addition five populations were from the mainland or from large islands close to it ("mainlands"). All 13 skerry and 5 island populations were located within $8 \mathrm{~km}$ distance of each other, in the Koster archipelago at the northernmost part of the Swedish west coast. The two remaining island populations were from an area about $70 \mathrm{~km}$ south of the Koster archipelago (BOR). The mainland populations were one from Tjärnö (TJÄ) $10 \mathrm{~km}$ east of Koster, two from Grötvik (GRO), and two from Hovs Hallar (HOV), 270 and $280 \mathrm{~km}$ south of Koster, respectively. The Koster populations inhabites smooth granite rocks exposed to wave action, while the other populations are from more or less sheltered habitats. The level of genetic variation were estimated by means of starch gel electrophoresis of 13 allozyme loci. (Methods and allele designations as in Ward and Warwick, 1980, and Janson and Ward, 1984.) Five of the loci (Aat-1, Pgm-1, Pgm2, Mpi, and $P g i$ ) were polymorphic when applying the 0.95 criterion of polymorphism, while the remaining eight $(M d h-1, I d h-1, O d h, X d h, S o d$, Est-1, Lap-1, and Ap-2) were monomorphic. Mean locus heterozygosity $\left(H_{\mathrm{L}}\right)$ were calculated from allele frequencies of the analysed loci, including monomorphic ones, for each population.

\section{RESULTS}

\section{Dispersal capacity}

The lack of a pelagic larva in this intertidal species suggests a very restricted dispersal rate between islands. A series of experiments was undertaken to test this assumption. The first one revealed that snails of $L$. saxatilis are unable to find their way back to the intertidal zone if detached from the substratum. Of 2126 marked snails released between 4 and $50 \mathrm{~m}$ from the shore (the area is almost atidal), and at 0.5 to $5 \mathrm{~m}$ depth, none reappeared on the shore although searched for repeatedly. Thus a bottom-bound migration between island habitats is unlikely, and in addition, if a snail is dislodged by waves, its chances of climbing another shore seem small.

In a second experiment, a small skerry, $2 \mathrm{~m}^{2}$ in size and $15 \mathrm{~m}$ from a nearby island, was depleted or nearly so, of $L$. saxatilis. More than 5000 snails were killed by scorching the substratum with a bottle-gasoline flame, on three successive days. Even after this treatment a few snails were found alive and these were removed by hand during repeated visits over more than a year. On 3rd June 1982 only one single male was found, and on 6th September the same year another male was recorded. During visits in the two following years (in August 1983 and in July 1984) no specimens were found. However, on 14th June 1985, 13 adults and about 50 juvenile snails appeared. The two largest ones were at least 3 years old, while the rest were not more than 2 years old. Five months later (13 November 1985) the total population size has increased enormously, and was estimated to be about 24,000 , the dominating part (95 per cent) being less than about 1.5 years old. This indicates that recolonisation rate is restricted, as no individuals were found during a period of 2 years. Those appearing during 1985 were either the offspring of one or a few snails which have escaped the scorching and the searching by hiding in small cracks in the rock, or they descended from one or a few immigrant specimens. Furthermore this experiment shows the extraordinary high rate of population growth which may take place in this species.

A third support for a low recolonisation rate is provided by the fact that 9 out of 30 small skerries visited lack a population of $L$. saxatilis. The mean height above low water level of these sites indicates that they have been potential habitats for $L$. saxatilis for, on average, 60 to 70 years. It is, of course, possible that something makes them less 
suitable as habitats, or alternatively, that once populated, strong selective forces have driven some of these skerry populations to extinction. However, I acquired a high respect for the survival capability of these snails when scorching the skerry for the third time without complete success.

My conclusion from these experiments is that migration rates between island populations are indeed low. The transport mechanism utilised by migrating snails is unknown, but drifting sea-weed or ice, and birds seem plausible suggestions (see e.g., Rees, 1965; Malone, 1965, for aerial dispersion of invertebrates).

\section{Genetic variation}

The genetic variation within and between the investigated populations are presented in table 1 , where allele frequencies of the five polymorphic loci are indicated as well as the level of heterozygosity within each population $\left(H_{\mathrm{L}}\right)$.

Populations of $L$. saxatilis differ genetically in allele frequencies on a large geographic scale, as well as over microgeographic distances $(<10 \mathrm{~m})$ (Ward and Warwick, 1980; Janson and Ward, 1984). In accordance with this, a gene diversity analysis (Nei, 1973) of the 18 populations from the Koster archipelago reveals differentiation of all five polymorphic loci over this area $\left(8 \mathrm{~km}^{2}\right)$, between 4 and 21 per cent being the fraction of between-population variation (table 2 ). This result indicates that the gene-flow between populations of the species is small, which again supports the conclusion that migration to the small and isolated skerry habitats is minimal.

Population heterozygosity $\left(H_{\mathrm{L}}\right.$, including monomorphic and polymorphic loci) ranges from 0.088 to 0.174 in the 25 populations analysed. Although there is an extensive overlap in the range of $H_{\mathrm{L}}$ of the three defined groups of populations, average values tend to increase with population size, that is, skerries are less heterozygote than islands which are in their turn less so than mainlands (table 3 ). No relationship is found, however, between population heterozygosity and either size or distance to nearby habitats within the skerry group (table 4). (Linear regressions being: $H_{\mathrm{L}}=b$ $\log$ (population size) $+a ; b=-0.0016 ; r=-0.08$; $p>0 \cdot 10$, and $H_{\mathrm{L}}=b \quad \log$ (distance) $+a ; \quad b=$ $-0.070 ; r=-0.29 ; p>0 \cdot 10$, respectively.)

\section{DISCUSSION}

One possible explanation to the small loss of heterozygosity within the skerry populations is that despite a low dispersal rate a few migrants each generation will be able to reach these isolated habitats. The genetic divergence between skerry and island populations in all five polymorphic loci, however, indicates that the exchange of migrants are less than about one per generation (e.g., Hartl, 1980). At such a low rate of migration stochastic processes within populations will be more important than gene flow between populations. Furthermore, with a gene flow affecting the genetic constitution of the skerry populations one expects smaller or distant populations to be less heterozygote than larger or nearby ones, and this is not the case.

Thus it seems likely that the overall level of heterozygosity is not set by the rate of migrants between populations, but rather by the events following the foundation of each population. The low immigration rate to skerry habitats suggests furthermore that there were bottlenecks during the foundation of these populations. Mayr's founder principle predicts that stochastic processes during a founder event will have large effects on the genetic constitution of the new population. In the skerry populations, the level of heterozygosity is reduced by about 10 per cent only, as compared to the island populations. This scarcely seems to fulfill the conditions for a "genetic revolution", to use the term of Mayr (1963). Why is this so?

Rapid population growth following a bottleneck will largely prevent a drop in the heterozygosity of a population (Nei et al., 1975). A small group of $L$. saxatilis populating a formerly empty habitat can increase dramatically in population size. $L$. saxatilis reproduces more or less continuously over the year, and females are able to store sperm and give birth to young for more than one year, in the absence of males (Janson, unpubl.). Yearly reproductive capacity is between 50 and 500 juveniles per female, depending on female size. In addition to this favourable reproductive pattern the type of selection acting is important as population expansion is promoted by a density-dependent component of selection. In wave exposed sites the snails occupy cracks and holes in the rocky surface, and the density of the species in these environments is strongly correlated with the availability of small crevices (Faller-Fritsch, 1977; Raffaelli and Hughes, 1978; Hughes and Roberts, 1981). Selection pressure is therefore low at low densities.

One further point to consider is the effective population number of a small population or a founder group, as $N_{e}$ may vary, even if the "group" consists of one fertilized female only. This is because females mate repeatedly with different males (Saur, unpubl.) and possibly store sperm 
Table 1 Genetic variation in five polymorphic loci of 13 skerry, 7 island, and 5 mainland populations from the Koster archipelago (KOS), and from four geographically spread areas within $300 \mathrm{~km}$ of coast line on the Swedish west coast (HOV, GRO, BOR, and TJÄ). Mean locus heterozygosity $\left(N_{\mathrm{L}}\right)$ over all loci, including eight more or less monomorphic ones, is indicated for each population

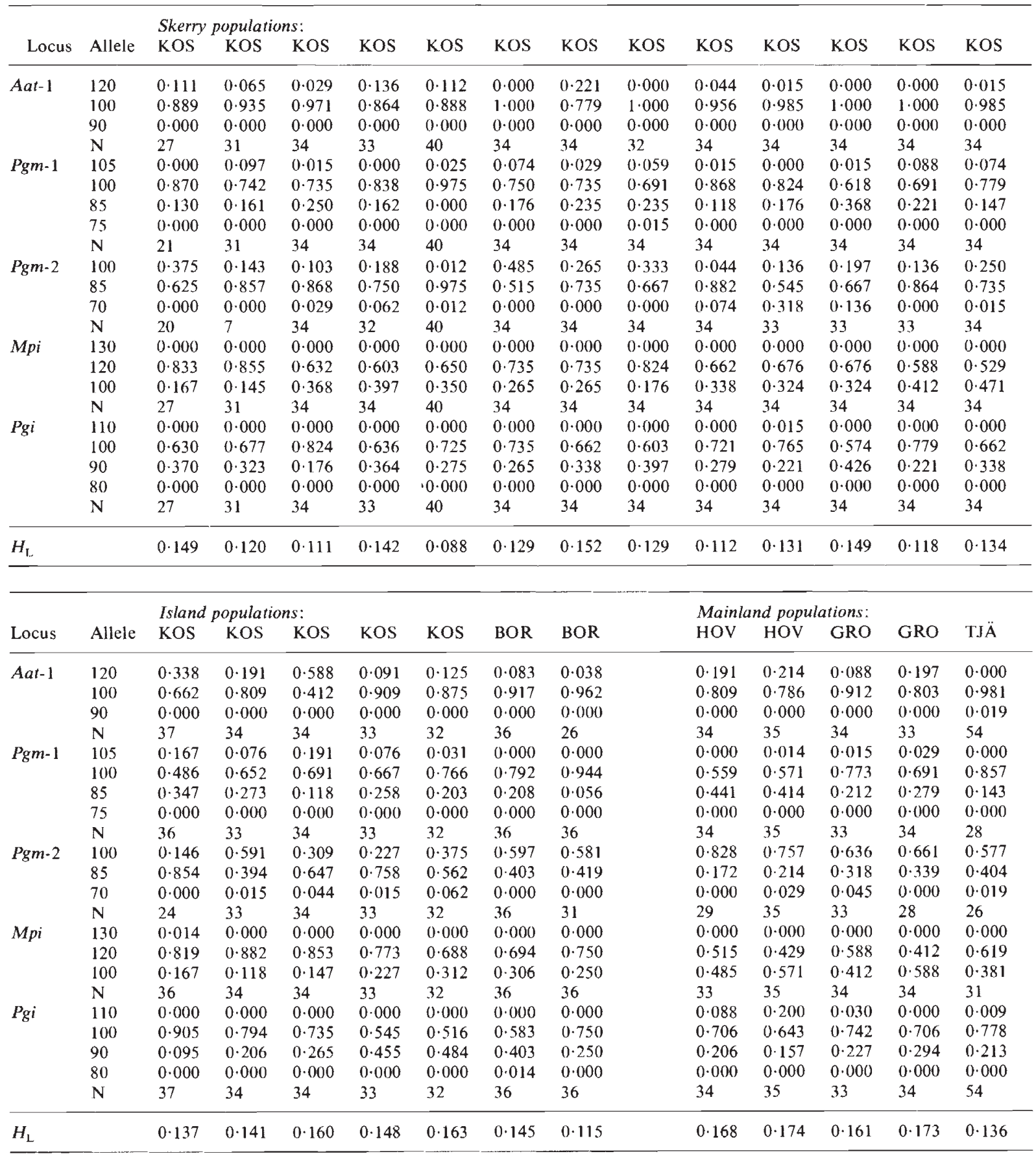


Table 2 Gene diversity analysis of 5 polymorphic loci in 18 populations of Littorina saxatilis from the Koster archipelago

\begin{tabular}{lllllll}
\hline Locus & $H_{\mathrm{T}}$ & $H_{\mathrm{P}}$ & $D_{\mathrm{PT}}$ & $G_{\mathrm{P}}$ & $G_{\mathrm{PT}}$ & $\chi^{2}$ \\
\hline Aat -1 & 0.205 & 0.162 & 0.043 & 0.791 & 0.209 & $252 \cdot 5^{*}$ \\
Pgm-1 & 0.405 & 0.383 & 0.022 & 0.946 & 0.054 & $125 \cdot 9^{*}$ \\
Pgm-2 & 0.426 & 0.378 & 0.049 & 0.886 & 0.114 & $283.4^{*}$ \\
Mpi & 0.401 & 0.380 & 0.021 & 0.948 & 0.052 & $79 \cdot 1^{*}$ \\
Pgi & 0.425 & 0.406 & 0.019 & 0.956 & 0.044 & $74.3^{*}$ \\
\hline
\end{tabular}

Gene diversity:

$H_{\mathrm{T}}$, total diversity

$H_{\mathrm{P}}$, within populations

$D_{\mathrm{PT}}$, between populations

$G_{\mathrm{P}}$, coefficient of within population differentiation

$G_{\mathrm{PT}}$, coefficient of between population differentiation

$\chi^{2}$, chi-squared for interpopulation heterogenity (Workman and Niswander, 1970)

$*, p<0.005$

Table 3 Levels of heterozygosity $\left(H_{\mathrm{L}}\right)$, within three distinct categories of populations (skerry, island, and mainland, see text for descriptions) of Littorina saxatilis from the Swedish west cost

\begin{tabular}{|c|c|c|c|}
\hline & Skerry & Island & Mainland \\
\hline $\begin{array}{l}\text { No. of popula- } \\
\text { tions }\end{array}$ & 13 & 7 & 5 \\
\hline Area $\left(\mathrm{m}^{2}\right)$, mean & $\begin{array}{l}25 \\
2-200\end{array}$ & $\begin{array}{l}3000 \\
400-10,000\end{array}$ & $\begin{array}{l}<\infty \\
<\infty\end{array}$ \\
\hline Habitat age (yr) & $20-40$ & $1000-4000$ & $<5000$ \\
\hline $\begin{aligned} H_{\mathrm{L}} & \text { mean } \\
& \text { range } \\
& \text { st. dev. }\end{aligned}$ & $\begin{array}{l}0 \cdot 128 \\
0 \cdot 088-0 \cdot 152 \\
0 \cdot 018\end{array}$ & $\begin{array}{l}0 \cdot 144 \\
0 \cdot 115-0 \cdot 163 \\
0 \cdot 016\end{array}$ & $\begin{array}{l}0 \cdot 162 \\
0 \cdot 136-0 \cdot 174 \\
0 \cdot 016\end{array}$ \\
\hline \multirow[t]{2}{*}{$\begin{array}{l}\text { Student's } t \\
\text { of differences }\end{array}$} & $\begin{array}{l}t_{18}=1.97 \\
0.05<p<0.10\end{array}$ & \multicolumn{2}{|c|}{$\begin{array}{l}t_{10}=1.92 \\
0.05<p<0.10\end{array}$} \\
\hline & \multicolumn{3}{|c|}{$\begin{aligned} t_{16} & =3.69 \\
p & <0.01\end{aligned}$} \\
\hline
\end{tabular}

Table 4 Habitat characteristics, population size estimates and mean heterozygosity $\left(H_{\mathrm{L}}\right)$ of 13 skerry populations of Littorina saxatilis from the Koster archipelago

\begin{tabular}{cclcc}
\hline $\begin{array}{l}\text { Habitat } \\
\text { area } \\
\left(\mathrm{m}^{2}\right)\end{array}$ & $\begin{array}{l}\text { Distance } \\
\text { to nearby } \\
\text { island }(\mathrm{m})\end{array}$ & $\begin{array}{l}\text { Height above } \\
\text { low water } \\
(\mathrm{m})\end{array}$ & $\begin{array}{l}\text { Population } \\
\text { size }\end{array}$ & $\begin{array}{c}H_{\mathrm{L}} \text { of } \\
13 \text { loci }\end{array}$ \\
\hline 2 & 100 & $0 \cdot 1$ & 1000 & $0 \cdot 111$ \\
2 & 3 & $0 \cdot 1$ & 6000 & $0 \cdot 129$ \\
$2 \cdot 5$ & 5 & $0 \cdot 4$ & 5000 & $0 \cdot 152$ \\
3 & 200 & $0 \cdot 1$ & 50 & $0 \cdot 120$ \\
5 & 100 & $0 \cdot 1$ & 50 & $0 \cdot 149$ \\
5 & 200 & $0 \cdot 1$ & 5000 & $0 \cdot 088$ \\
5 & 200 & $0 \cdot 2$ & 10,000 & $0 \cdot 129$ \\
8 & 170 & $0 \cdot 3$ & 20,000 & $0 \cdot 142$ \\
14 & 80 & $0 \cdot 2$ & 3000 & $0 \cdot 131$ \\
20 & 60 & $0 \cdot 2$ & 5000 & $0 \cdot 149$ \\
25 & 100 & $0 \cdot 3$ & 60,000 & $0 \cdot 112$ \\
30 & 450 & $0 \cdot 5$ & 5000 & $0 \cdot 118$ \\
200 & 2500 & $1 \cdot 0$ & 50,000 & $0 \cdot 134$ \\
\hline
\end{tabular}

from a number of males simultaneously. This increases the effective number of the females somewhat, as effective population size is given by: $N_{e}=$ $4 N_{f} N_{m} /\left(N_{f}+N_{m}\right)$, where $N_{f}$ and $N_{m}$ are numbers of females and males, respectively (Wright, 1938). One fertilised female will thus have an effective size of between 2 and 4 .

Let us consider a population bottleneck of one L. saxatilis female who initiates a new population in a skerry. In the simplest case the population will increase according to the logistic growth equation, which emphasises density-dependent regulation. Assuming the carrying-capacity of the skerry to be 10,000 , population size will increase as in fig. 1 for the different values of intrinsic growth rate $(r): 0 \cdot 7,1 \cdot 6,2 \cdot 3$, and $4 \cdot 6$, which correspond to a yearly multiplication rate of $2,5,10$, and 100 , during the exponential phase of population increase. Although the net reproductive rate of a female might possibly be high enough to satisfy an $r$ value of $4 \cdot 6$, it seems more likely that juveniles, to a certain degree, will suffer from densityindependent mortality such as extreme temperature and salinity, and risk of desiccation, will kill less tolerant juveniles. Nevertheless an $r$ value of 2 is possible even if the density-independent component of juvenile mortality is 90 per cent.

The stochastic decline in heterozygosity over a bottleneck is given by the recurrence formula: $H_{n+1}=H_{0}\left(1-1 / 2 N_{0}\right)\left(1-1 / 2 N_{1}\right)\left(1-1 / 2 N_{2}\right) \ldots$ $\left(1-1 / 2 N_{n}\right)$, (Barton and Charlesworth, 1984), where $H_{0}$ is the heterozygosity of the ancestral population and $N_{0}$ and $N_{n}$ are the effective population sizes of the founder group, 0 and $n$ generations

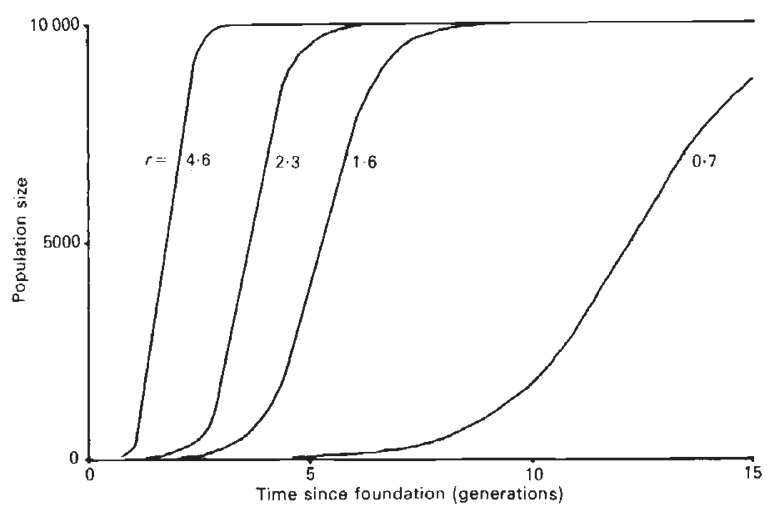

Figure 1 Expansion of a skerry population founded by a small group of Littorina saxatilis, assuming logistic growth and a carrying capacity of 10,000 . The size of the founder group $\left(N_{0}\right)$ is 2 , and intrinsic rate of increase $(r)$ is $0 \cdot 7,1 \cdot 6,2 \cdot 3$, and $4 \cdot 6$, which corresponds to a multiplication rate of 2 , 5,10 , and 100 , within the exponential phase of growth, respectively. 
after the foundation. The relationship between $H_{n}$ and $H_{0}$ is outlined in fig. 2 for the growth rates assumed in fig. 1. If the intrinsic growth rates of the population is 2 or more, heterozygosity levels will fall about 10 per cent only, even if the bottleneck size is extremely small. Thus if $L$. saxatilis populations which inhabit the small skerries have passed through severe bottlenecks, the observed drop in heterozygosity is not more than expected from theory, assuming a rapid population increase; an assumption supported by the rate of growth of the experimentally depleted population.

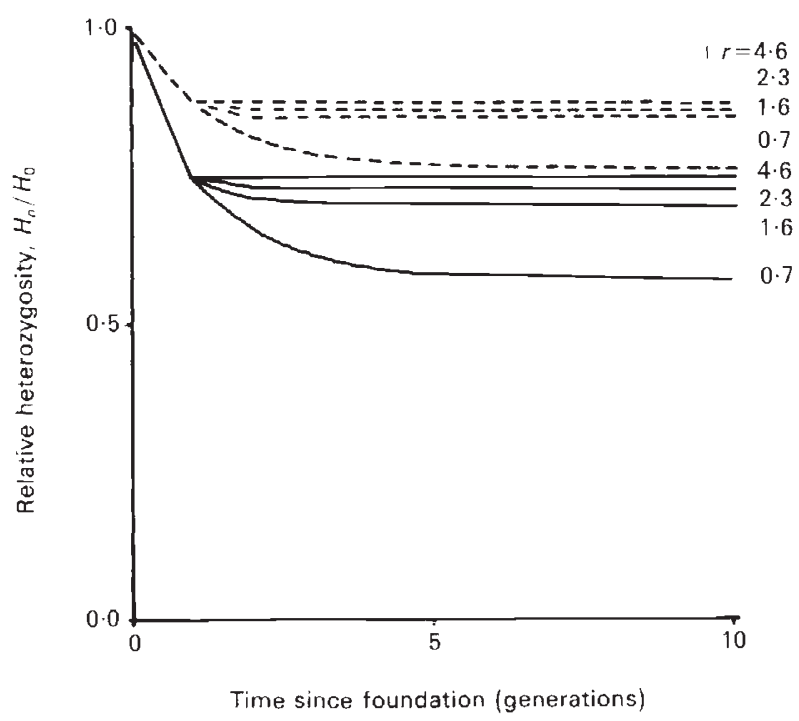

Figure 2 Levels of heterozygosity within a recently founded population. $N_{0}$ of the founder group is 2 (solid), or 4 (dashed). $H_{0}$ is the heterozygosity of the ancestral population, and $H_{\mathrm{n}}$ is the heterozygosity of the founded population after $\mathrm{n}$ generations. (Generation time in Littorina saxatilis is about 1 year.) Logistic growth, as in fig. 1, is assumed for different values of intrinsic growth rate, $r$.

As discussed by Nei et al. (1975), equilibrium levels of heterozygosity will be restored, by the accumulation of new mutations, only after a considerable time. The discrepancy in heterozygosity between island and mainland populations, albeit small, might suggest that the former were established soon after they appeared above the water surface, some thousands of years ago, so that these younger island populations are one step behind in the progress towards the equilibrium level of heterozygosity-which according to Nei et al. (1975) will demand roughly $10^{6}$ generations, or more, to achieve.
Thus although bottlenecks are likely to occur when small and isolated habitats are founded, the "founder-principle" as a powerful force inducing genetic alterations leading to potential situations of speciation, is probably not important in this and in related species with similar ecology and reproductive system.

Acknowledgements I thank B. Charlesworth for comments on an earlier draft of the manuscript, and several colleagues and a referee for helpful criticism and discussion during the preparation of this piece of work.

\section{REFERENCES}

BARTON, N. H. AND CHARLESWORTH, B. 1984. Genetic revolutions, founder effects, and speciation. Ann. Rev. Ecol. Syst., 15, 133-164.

CARSON, H. I. 1975. The genetics of speciation at the diploid level. Amer. Nat., 109, 83-92.

CHAKRABORTY, R., AND NEl, M. 1977. Bottleneck effects on average heterozygosity and genetic distance with the stepwise mutation model. Evolution, 31, 347-356.

FALLER-FRITSC:H, R. J. 1977. Reproductive strategies of the winkle Littorina rudis in relation to population dynamics and size structure. In Keegan et al. (ed.), Biology of Benthic Organisms. Pergamon Press, Oxford.

HARTL, D. L. 1980. Principles of population genetics. Sinauer, Sunderland, Mass.

HUciHES, R. N. AND ROBERTS, D. J. 1981. Comparative demography of Littorina rudis, $L$. nigrolineata and $L$. neritoides on three contrasted shores in north Wales. $J$. Anim. Ecol., 50, 251-268.

JANSON, K. AND WARD, R. D. 1984. Microgeographic variation in allozyme and shell characters in Littorina saxatilis Olivi (Prosobranchia: Littorinidae). Biol. J. Linn. Soc., 22, 289307.

LANIF,, R. 1980. Genetic variation and phenotypic evolution during allopatric speciation. Amer. Nat., 116, 463-479.

LEWONTIN, R. C. 1965 . Discussion of a paper by Dr. Howard. In Baker and Stebbins (ed.), The Genetics of Colonizing Species. Academic Press, New York.

MALONE, C. R. 1965. Killdeer (Charadrius vociferus Linnaeus) as a means of dispersal for aquatic gastropods. Ecology, $46,551-552$.

MAYR, E. 1963. Animal Species and Evolution. Harvard Univ. Press, Cambridge, Mass.

NEI, M. 1973. Analysis of gene diversity in subdivided populations. Proc. Nat. Acad. Sci. USA, 70, 3321-3323.

NEl, M., MARUYAMA, T. AND CHAKRABORTY, R. 1975. The bottleneck effect and genetic variability in populations. Evolution, 29, 1-10.

RAFFAELLI, D. G. AND HUGHES, R. N. 1978. The effects of crevice size and availability on populations of Littorina rudis and Littorina neritoides. J. Anim. Ecol., 47, 71-83.

REF.s, W. J. 1965. The aerial dispersal of mollusca. Proc. Malac. Soc. Lond., 36, 269-282.

TEMPLETON, A. R. 1980. The theory of speciation via the founder principle. Genetics, 94, 1011-1038.

WARD, R. D. AND WARWICK, T. 1980. Genetic differentiation in the molluscan species Littorina rudis and Littorina arcana (Prosobranchia: Littorinidae). Biol. J. Linn. Soc., 14, 417-428 
Workman, P. L. AND Niswander, J. D. 1970. Population studies on southwestern Indian tribes. II. Local genetic differentiation in the Papago. Amer. J. Human Gen., 22, 24-49.
WRIGHT, S. 1932. The roles of mutation, inbreeding, crossbreeding and selection in evolution. Proc. 6th Int. Congr. Genet., $1,356-366$.

WRIGHT, S. 1938. Size of population and breeding structure in relation to evolution. Science, $87,430-431$. 